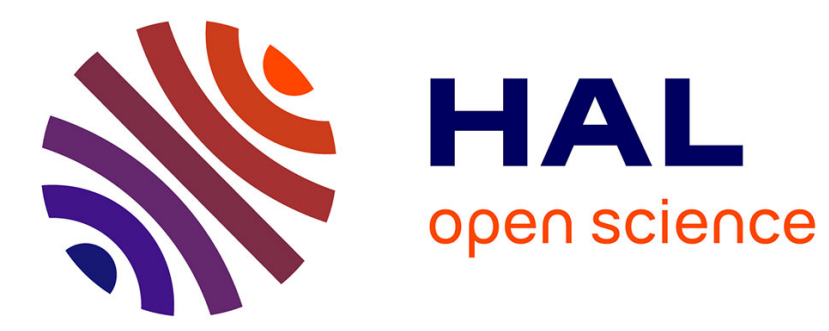

\title{
Survival analysis in two lines of rabbits selected for reproductive traits
}

\author{
M. Piles, Herve H. Garreau, O. Rafel, Catherine Larzul, J. Ramon, Vincent
}

Ducrocq

\section{- To cite this version:}

M. Piles, Herve H. Garreau, O. Rafel, Catherine Larzul, J. Ramon, et al.. Survival analysis in two lines of rabbits selected for reproductive traits. Journal of Animal Science, 2006, 84, pp.1658-1665. hal-02658061

\section{HAL Id: hal-02658061 https://hal.inrae.fr/hal-02658061}

Submitted on 30 May 2020

HAL is a multi-disciplinary open access archive for the deposit and dissemination of scientific research documents, whether they are published or not. The documents may come from teaching and research institutions in France or abroad, or from public or private research centers.
L'archive ouverte pluridisciplinaire HAL, est destinée au dépôt et à la diffusion de documents scientifiques de niveau recherche, publiés ou non, émanant des établissements d'enseignement et de recherche français ou étrangers, des laboratoires publics ou privés. 


\title{
Survival analysis in two lines of rabbits selected for reproductive traits ${ }^{1}$
}

\author{
M. Piles, ${ }^{* 2}$ H. Garreau, $\dagger$ O. Rafel,* C. Larzul,, J. Ramon, $*$ and V. Ducroc ${ }^{2} \neq$
}

:Unitat de Cunicultura, Institut de Recerca i Tecnologia Agroalimentàries (IRTA) Unitat de Cunicultura, 08140 Caldes de Montbuí, Barcelona, Spain; †Institut National de la Recherche Agronomique (INRA) Station d'Amélioration Génétique des Animaux, 31326 Castanet-Tolosan, France; 1 Institut National de la Recherche Agronomique (INRA) Station de Génétique Quantitative et Appliquée, 78352 Jouy-en-Josas, France

\begin{abstract}
The objective of the study was to analyze the reproductive longevity of 2 selected lines of rabbits. The first one was the Prat line, a line selected in Spain on litter size at weaning, and raised in overlapping generations. The second one was a French line, the A1077 line, selected on litter size at birth and individual weight at $63 \mathrm{~d}$ of age, managed in batches, and artificially inseminated with discrete generations. Reproductive longevity was measured beginning at the first successful mating, assessed by a pregnancy diagnosis in the Prat line, and at the first kindling in the A1077 line. In the A1077 line, culling for infertility occurred after 3 unsuccessful artificial inseminations. The trait analyzed, defined as the doe length of productive life (LPL), was the time in days between date of the first positive pregnancy diagnosis and date of culling or death in the Prat line. In the A1077 line, the trait was
\end{abstract}

the number of AI after the first kindling. Effects included in the model were year-season, litter size at birth, reproductive cycle or physiological status $x$ cycle interaction, age at first mating, batch (only for the A1077 line), and additive genetic value of the animal as a random effect. Survival analyses were carried out with a Cox model for the Prat line and a discrete model for the A1077 line. The estimated heritability values for LPL were around 0.16 in the Prat and A1077 lines with a model including physiological status $\times$ cycle interaction effect. Removing this effect from the model led to an increase in estimated genetic variance with $\mathrm{h}^{2}=0.24$ and 0.19 in the Prat and A1077 lines, respectively. Including the traits LPL and number of AI from first fertile mating or AI in selection programs could increase reproductive longevity and decrease the replacement rate.

Key words: genetic parameter, longevity, rabbit, survival analysis

(c)2006 American Society of Animal Science. All rights reserved.

J. Anim. Sci. 2006. 84:1658-1665 doi:10.2527/jas.2005-678

\section{INTRODUCTION}

In meat rabbit production, the doe replacement rate is about $120 \%$ (Rafel et al., 2001) with about $50 \%$ of the dead or culled does replaced during their first 3 production cycles (Rosell, 2003). The main problems associated with high replacement rate are the replacement cost of the does, the greater frequency of less mature females (young does are still growing and are less immunologically mature at parturition, showing lower litter size and more health problems), and sometimes the management and pathological problems re lated to introduction of animals from other farms. All

\footnotetext{
'Acknowledgments: Research was supported by Departament d'Universitats, Recerca i Societat de la luformació de la Generalitat de Catalunya.

${ }^{2}$ Corresponding author: miriam.piles@irtacs

Received November 22,2005 .

Accepted February 20, 2006.
}

of these considerations lead to a strong interest in increasing reproductive longevity, defined as the ability of the female to delay involuntary culling. Despite its importance, longevity has not been included in rabbit selection programs. The difficulty in improving longevity through conventional breeding methods is mainly due to its low heritability and the time needed to obtain relevant information. However, in mice, it has been shown that reproductive life and number of parities can be improved by selection on phenotypic performance (Farid et al., 2002). In rabbits, studies on reproductive life were conducted considering number of litters or length of life (Youssef et al., 2000), number of matings or age at culling (Lukefahr and Hamilton, 2000), or culling rate (Tudela et al., 2003). But in rabbit breeding systems, does are generally all culled together after 1 to $2 \mathrm{yr}$, to be replaced by a new generation. Censoring rate is not negligible and must be properly taken into account in longevity studies. The aim of this study was to assess doe longevity in 2 different lines and breeding systems and to analyze the genetic variability of this 
trait to introduce it as a selection criterion in selection schemes.

\section{MATERIALS AND METHODS}

Research protocol was approved by the animal care and use committee.

\section{The Prat Line}

The first data set included animals that belong to a rabbit line selected in Spain for litter size at weaning (Gómez et al., 2002). They were housed on the farm of the Institut de Recerca i Tecnologia Agroalimentàries, which has insulated roof and walls, controlled lighting and ventilation, and a cooling-system to avoid high temperatures in summer. Does followed a semintensive reproductive rhythm, with first mating at about $4.5 \mathrm{mo}$ of age and with postpartum intervals of $42 \mathrm{~d}$. Generations were overlapping. Data were collected from June 1992 to December 2002. There were 3,250 records from daughters of 522 sires. The trait studied here was the doe length of productive life (LPL), defined as the number of days between the date of the first positive diagnosis of gestation and date of culling.

Does were never culled based on production results. Does nonpregnant after diagnosis of pregnancy were culled only if a pathological problem was observed independently from mating order $(1,2, \ldots)$ or in the extreme case of nonpregnant does after a high (but not defined) number of matings for does that did not show visible symptoms of illness but were considered to have a reproductive problem. Therefore, LPL clearly reflected reproductive longevity, defined as the ability to delay involuntary culling. Only records from does removed to free space for new does or eliminated because of accidents or other technical reasons not related to health status were treated as censored. There were 1,722 right-censored records $(52.9 \%)$ and $1,528(47.1 \%)$ uncensored records, corresponding to those does whose complete career had been observed. Average LPL was about 234 d (range: from 3 to $698 \mathrm{~d}$, median: $258 \mathrm{~d}$ ) at censoring for does with censored records and approximately 128 d (range: from 3 to $634 \mathrm{~d}$, median: $109 \mathrm{~d}$ ) for does with complete records. Pedigrees were traced back and included 4,498 animals. The average number of daughters per sire was 5.94, varying from 1 to 25 daughters.

\section{The A1077 Line}

The A1077 line, which originated from a New Zealand strain, was selected on litter size at weaning from 1972 to 1993 (Rochambeau et al., 1998). Since 1993, it has been selected for number of rabbits born alive per litter and individual body weight at $63 \mathrm{~d}$. The line was raised on an Institut National de la Recherche Agronomique experimental farm (Langlade, France) in a ventilated and light-controlled building. Does were managed in a batch system: the does from one batch were all of the same age, were first inseminated at the age of 4 mo, and subsequently were inseminated once every $6 \mathrm{wk}$. No diagnosis of pregnancy was performed. Culling occurred if any pathological problem was detected in the doe or after 3 successive unsuccessful AI, without any other consideration. Generations were discrete. Data were collected from 1995 to 2002 over 10 generations (G23 to G32) and consisted of 1,352 does from 220 sires. The pedigree file included 1,712 animals. The trait analyzed here was the number of Al from the first successful AI (with birth) to the last AI. The records of does still in production at the end of a generation (15 or 16 AI; i.e., about 20 mo of age) were considered as rightcensored $(37 \%)$. Average number of AI was about 11 for does with censored records and 5.8 for does with complete records. The average number of daughters per sire was 6.06, varying from 1 to 25 daughters.

\section{Statistical Analysis}

Model. Data were analyzed using survival analysis. This approach allows the use of parametric or semiparametric models, for continuous or discrete data, with time-dependent factors and censored records. The hazard function of an individual $i(i=1 \ldots n)$ at time $t$ is modeled as

$$
\lambda_{i}(t)=\lambda_{0}(t) \exp \left[x_{i}^{\prime}(t) \beta+a_{i}\right]
$$

where $\lambda_{0}(t)$ is the baseline hazard at time $t, x_{i}^{\prime}(t) \beta$ represents the fixed effects, and $\alpha_{i}$ is the animal effect.

A nonparametric graphical test based on a plot of $\log \left(-\log \left[\mathrm{S}_{\mathrm{KM}}(\mathrm{time})\right]\right)$ vs. $\log ($ time $)$, was performed to check whether the Weibull function was adequate as a baseline hazard function. $S_{K M}($.$) is the Kaplan-Meier$ (i.e., nonparametric) estimate of the survival curve (Klein and Moeschberger, 1997). This plot should display a straight line. Considering the negative results (not shown), baseline hazard functions were described with 2 different models for the 2 strains, taking into account the characteristics of the traits chosen to measure longevity, which were continuous for the Prat line and discontinuous for the A1077 line. Therefore, data from the Prat line were analyzed using a semiparametric Cox model. For data from the A 1077 line, the method described by Prentice and Gloeckel (1978) and extended to frailty models was applied because it is more appropriate for discrete data (Ducrocq, 1999). This corresponds to a different definition of time: number of days in the Prat line and number of $\mathrm{AI}$ in the A1077 line. The Kaplan-Meier estimates of the survival curves are shown in Figures 1 and 2 for the Prat and A1077 lines, respectively.

Effects. For the Prat line, the following factors were included in the final model:

i. Wither a time-dependent cycle effect, with 3 levels indicating first, second, or later reproductive cycle to take into account the parity of the doe, or a timedependent physiological status $\times$ cycle interaction 


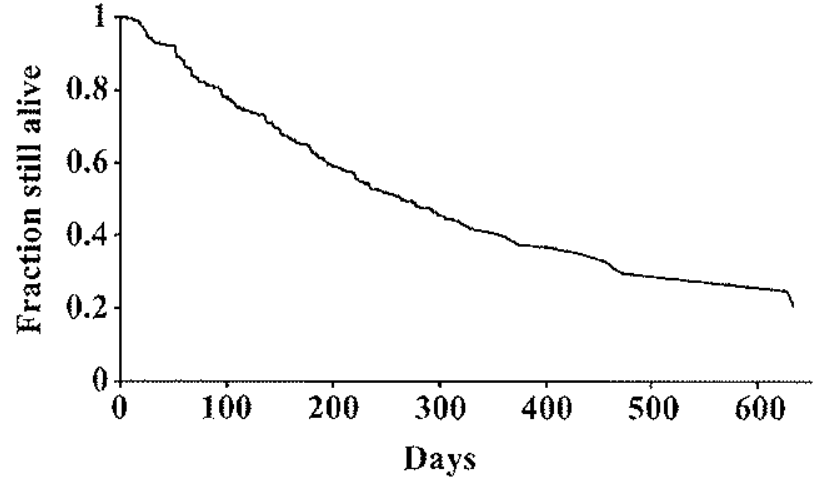

Figure 1. Kaplan-Meier survival curve for the Prat line.

(PSC) effect of the cycle (first, second, and later) by status (empty, pregnant, pregnant and suckling, and suckling), describing different stages during the reproductive cycles that could lead to differences in culling risk. Changes of level occurred at different times of the cycle depending on the doe's fertility (success to conception) in the previous and current cycles. Therefore, the times of change were calculated for each doe and each cycle.

ii. Year-season (YS), considered as a time-dependent effect with 42 classes defined as intervals of 3 mo length from June 1992 (included) to December 2002.

iii. Litter size (LS), time-dependent factor with 9 classes defined as follows: nulliparous, 0,1 to 2,3 to 4,5 to 6,7 to 8,9 to 10,11 to 12 , or $>12$ born alive. Changes of level occur at time of parturition.

iv. Age at first fertile mating, time-independent continuous covariate expressed in clays that considers possible differences in culling risk between does due to differences in the age when they began their reproductive career. Both linear and quadratic terms were considered in the analysis.

v. Animal: a random time-independent effect of the additive genetic value of the animal, assumed to follow a multivariate normal distribution with mean zero and variance $\mathbf{A} \sigma_{g}^{2}$, where $\mathbf{A}$ is the rela-

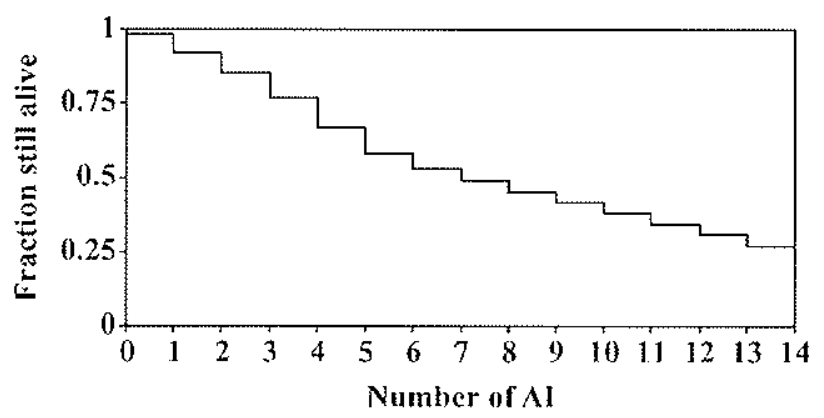

Figure 2. Kaplan-Meier survival curve for the French A1077 line.

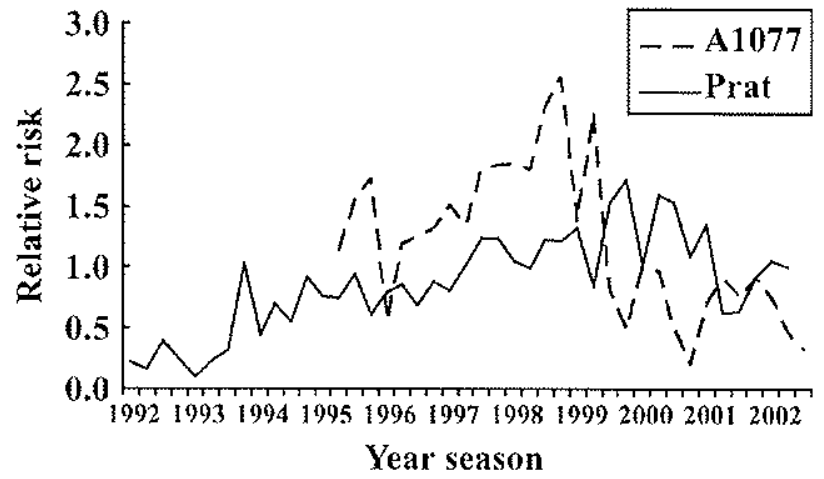

Figure 3. Effect of year-season on relative risk of culling.

tionship matrix and $\sigma_{g}^{2}$ is the variance associated with the animal effect. Only the direct genetic effect was considered.

For the French A1077 line, similar effects were included in the model:

i. Either a time-dependent cycle effect, with 3 levels indicating the parity of the doe ( $1,2,3$ or more), or a time-dependent PSC interaction, effect of the cycle (1, 2,3 or more) combined with the physiological status of the doe at the moment of AI (suckling, nonsuckling). The nonsuckling status means that the previous $\mathrm{AI}$ was unsuccessful or the number of rabbits born alive was null.

ii. Year-season, a time-dependent effect with 32 classes defined as intervals of 3 mo length.

iii. Litter size, a time-dependent effect with 8 classes as before $(0,1$ to 2,3 to 4,5 to 6,7 to 8,9 to 10 , 11 to 12,13 or more). Changes of level occur at time of parturition. Because only females with at least 1 litter were considered in the analysis, there were no nulliparous does.

iv. Batch, time-independent effect of group of does that began production at the same time, with 19 levels ( 2 cohorts per generation except for $G 24, G$ 25 , and $\mathrm{G} 26$ with a single cohort).

v. Age at first fertile mating, a time-independent covariate as described before, considered in linear and quadratic terms.

vi. Animal, the random time-independent direct genetic effect.

The analyses were first performed without the animal effect to determine the fixed effects that were significant and to compare the models with cycle effect or PSC interaction. Then the analyses were performed including the animal effect to estimate the genetic variance for the traits LPL and number of Al from first fertile mating or AI. All analyses were performed using the Survival Kit (Ducrocq and Sölkner, 1998).

The effective heritability was calculated as $\mathrm{h}^{2}=$ $\frac{\sigma_{\mathrm{g}}^{2}}{\sigma_{\mathrm{g}}^{2}+1}$ in each line. This formula corresponds to the extension to the Cox and discrete survival animal mod- 
Table 1. Likelihood ratio test for the Prat line, with factors sequentially added to the fixed effects model, with cycle (C) effect or with physiological status $\times$ cycle (PSC) inter action

\begin{tabular}{|c|c|c|c|c|c|c|}
\hline \multirow[b]{2}{*}{ Factor $^{1}$} & \multicolumn{3}{|c|}{ With C effect } & \multicolumn{3}{|c|}{ With PSC interaction } \\
\hline & $x^{2}$ & $\mathrm{DF}$ & $P$ value & $x^{2}$ & $\mathrm{DF}$ & $P$ value \\
\hline $\mathrm{C}$ or PSC & 730.52 & 2 & $<0.001$ & 1466.90 & 10 & $<0.001$ \\
\hline YS & 178.24 & 41 & $<0.001$ & 236.92 & 41 & $<0.001$ \\
\hline LS & 177.29 & 8 & $<0.001$ & 82.72 & 7 & $<0.001$ \\
\hline AGE & 0.42 & 1. & 0.517 & 0.61 & 1 & 0.436 \\
\hline $\mathrm{AGE}^{2}$ & 3.07 & 1 & 0.078 & 6.54 & 1 & 0.011 \\
\hline
\end{tabular}

${ }^{1}$ YS $=$ year-season; LS = litter size; $A G Q$ = age at first insemination.

els of the formula of Yazdi et al. (2002) developed for a Weibull sire model. This extension was validated for the Cox model through simulation by J. P. Sánchez (personal communication, Universidad Politécnica de Valencia, Spain), and the rationale for also using it for the discrete model is the possible reparameterization of this model into a particular Weibull model (Ducroca, 1999). The effective heritability is the heritability on the original scale. It is the one that can be used to compute approximate reliabilities or expected genetic gains similar to the classical linear mixed model. These heritability estimates are maximum values, considering that all records are uncensored. If the proportion of uncensored records until a given time is $p$, the value of $h^{2}$ such that the reliability can be computed using the index of selection formula (equivalent heritability), is given by the expression $h_{\mathrm{e}(\xi u i}^{2}=\frac{\sigma_{\mathrm{g}}^{2}}{\sigma_{\mathrm{g}}^{2}+\frac{1}{\mathrm{p}}}$ (Yazdi et al., 2002).

\section{RESULTS AND DISCUSSION}

\section{Choice of Model}

Tables 1 and 2 show the likelihood ratio tests comparing nested models, with factors sequentially added to the fixed effects model for the Prat line and the A1077 line, respectively. All effects were significant except age for the Prat line (but age ${ }^{2}$ was significant; therefore, age was kept in the model) and age ${ }^{2}$ in the A1077 line. Two models including the cycle or cycle by physiological status effects in addition to the other factors were compared using the Akaike Information Criterion (AIC). The best model is the 1 that minimizes AIC $=-2 \ln (\mathrm{L})$ $+2 p$, where $L$ is the maximum value of the likelihood function and $p$ is the number of estimable parameters. In both the Prat and A1077 lines, the lowest AIC value corresponded to the model with cycle by physiological status effect with a decrease in AIC of 686 and 21 for the Prat and A1077 lines, respectively.

\section{Choice of Trait}

Unlike Sánchez et al. (2004), who studied LPL from the first mating, the beginning point of productive life in the current study was the first fertile event, defined by positive pregnancy diagnosis in the Prat line and by first parturition in the A1077 line. In agreement with Sánchez et al. (2004), the baseline hazard function failed to fit a Weibull hazard function, for the same reason (a high proportion of deaths in first parturition). Consequently, the semiparametric Cox model was chosen for the Prat line. In the A1077 line, culling and deaths were mainly observed just after parturition, every 42 d. Yazdi et al. (1999) compared estimation of sire variance with 2 models, a continuous model with a Weibull baseline hazard function and a discrete model. Based on a large data set, they concluded that sire variance estimation was moderately affected by the model and suggested use of a Weibull baseline hazard function because of its robustness. In a previous study, Garreau et al. (2001) concluded that, in a rabbit population, a Weibull baseline hazard function underestimated the survival rate after the eighth $\mathrm{AI}$, and that the sire variance estimation was affected by the choice of a continuous or discrete model. Thus, for the A1077 line, a continuous model was not considered appropriate, and a discrete model was applied.

\section{Relative Risk for YS Effects}

The relative risk for each level of the factor YS with respect to the last level in the Prat line is shown in

Table 2. Likelihood ratio test for the French A1077 line, with factors sequentially added to the fixed effects model, with cycle (C) effect or with physiological status $\times$ cycle (PSC) interaction

\begin{tabular}{lcccccc}
\hline & \multicolumn{3}{c}{ With Geffect } & \multicolumn{3}{c}{ Witl PSC interaction } \\
\cline { 2 - 6 } Factor $^{1}$ & $x^{2}$ & DF & Pvalue & $x^{2}$ & DF & $P$ value \\
\hline Cor PSC & 8.8007 & 2 & 0.0123 & 37.056 & 4 & $<0.001$ \\
COHORT & 107.51 & 16 & $<0.001$ & 110.61 & 16 & $<0.001$ \\
YS & 88.96 & 29 & $<0.001$ & 84.787 & 29 & $<0.001$ \\
LS & 42.886 & 7 & $<0.001$ & 41.175 & 7 & $<0.001$ \\
AGE & 9.2599 & 1 & 0.0023 & 9.6084 & 1 & 0.0019 \\
AGE $^{2}$ & 0.0348 & 1 & 0.8521 & 0.0588 & 1 & 0.8085 \\
\hline
\end{tabular}

${ }^{1} \mathrm{YS}=$ year-season; $\mathrm{LS}=\mathrm{litter}$ size; $\mathrm{AGE}=$ age at first fertile mating. 


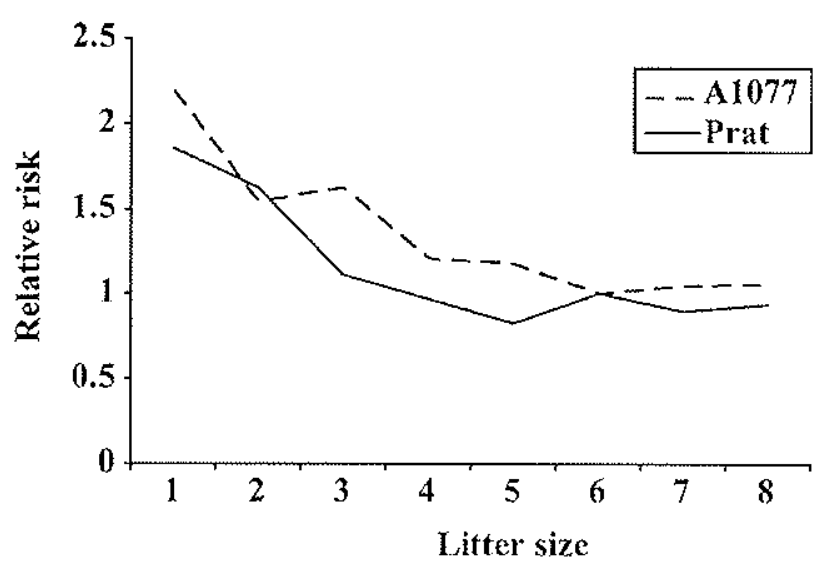

Figure 4. Effect of litter size on relative risk of culling. Levels correspond to 0,1 to 2,3 to 4,5 to 6,7 to 8,9 to 10,11 to 12,13 or more kits, respectively.

Figure 3. Greater values corresponded to the interval from 1998 to 2001 , probably due to the greater disease incidence (mainly enteropathy) during this period. The relative risk for each level of the factor YS in the A1077 line is also shown in Figure 3 . The relative risk tended to increase until the late 1990 s and then remained below 1. This trend can be explained by the use of new individual cages for the young does before their first AI, which has considerably improved their health since 2000 .

\section{Relative Risk for LS Effect}

In the Prat line (Figure 4), the first level (0) of the LS effect, corresponding to nulliparous does, was confounded with the first level of the PSC factor and is not shown. In the A1077 line (Figure 4), the nulliparous level did not exist because longevity was considered only for does with at least 1 kindling (i.e., 1 litter with at least 1 rabbit born alive). For the other levels, the effect of LSS was very similar in both lines, with a high risk of culling for does with a null LS and very small differences for the other levels. Longevity does not seem to be unfavorably influenced by large I.S. Similarly, increasing LS by selection did not increase culling rate (Tudela et al., 2003). The very high risk of culling for nulliparous does, as well as the greater risk for very low LS ( 0 or 1 kit per litter), was also observed in the V strain (Sánchez et al., 2004), another rabbit line selected on Ls in Spain. In the Prat line, as well as in the $V$ line, there was no voluntary culling for productive reasons. The greater risk of culling associated with low LS could be related to underlying pathological problems. In the A1077 line, voluntary culling was practiced for infertile does with 3 successive Al with no kindling, and the relative risk for low LS was of the same magnitude as in the Prat and $V$ lines. One potential interpretation is that infertility and very low LS result from the same pathological problems.

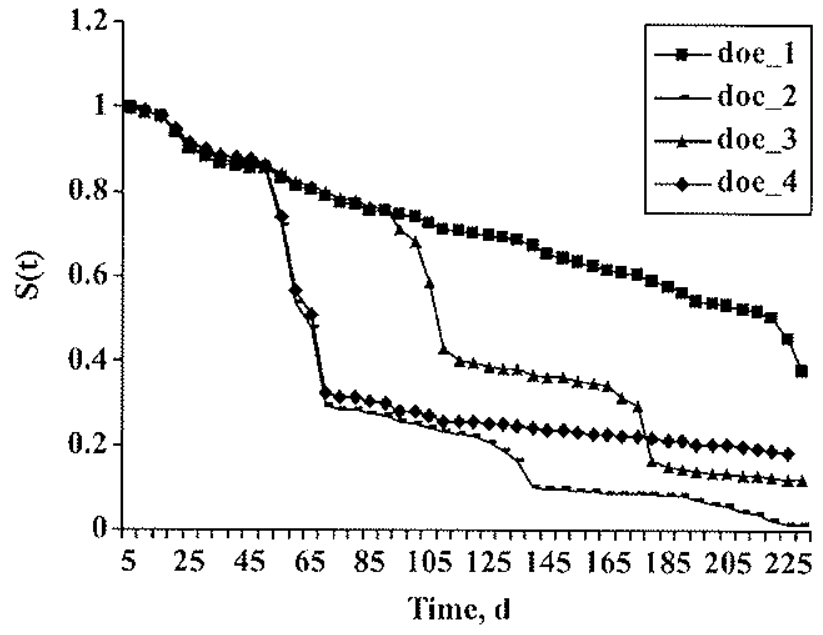

Figure 5. Survival functions $S(t)$ of does with different reproductive behavior in the Prat line. Doe no. 1: Doe with 6 42-d cycles. Doe no. 2: Doe with three 70-d cycles. Doe no. 3: Doe with first cycle of $42 \mathrm{~d}$ in length and 3 more cycles of $70 \mathrm{~d}$ in length. Doe no. 4: Doe with first cycle of $70 \mathrm{~d}$ in length and 4 more cycles of $42 \mathrm{~d}$ in length.

\section{Relative Risk for PSC Effect}

To evaluate the effect of the combination of cycle with physiological status of the female, it is necessary to account for the simultaneous change in the baseline hazard function and cycle number with time (Gröhn ef al., 1997). Late cycles are always associated with larger values of $t$. The corresponding hazard is the product of the specific cycle (or PSC) effect and the baseline hazard. One way to better visualize the combination of the 2 is by calculating the expected survival curve for typical does. Figure 5 shows the estimated survival functions of 4 Prat does with different reproductive behavior (different stages or length of reproductive cycles) but with the same levels for the other factors in the

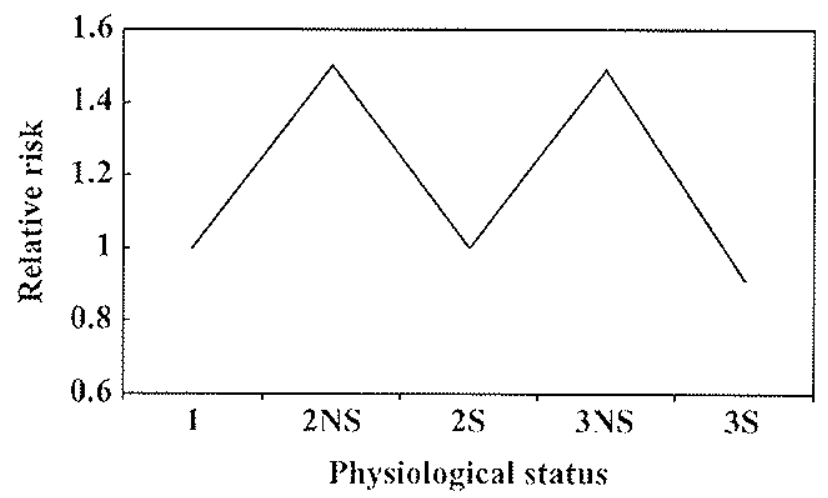

Figure 6. Physiological status within cycle effect in the A1077 line; $S=$ Suckling, $N S=$ Nonsuckling; $1=$ first parity; $2=$ second parity; $3=$ third and later parity. 


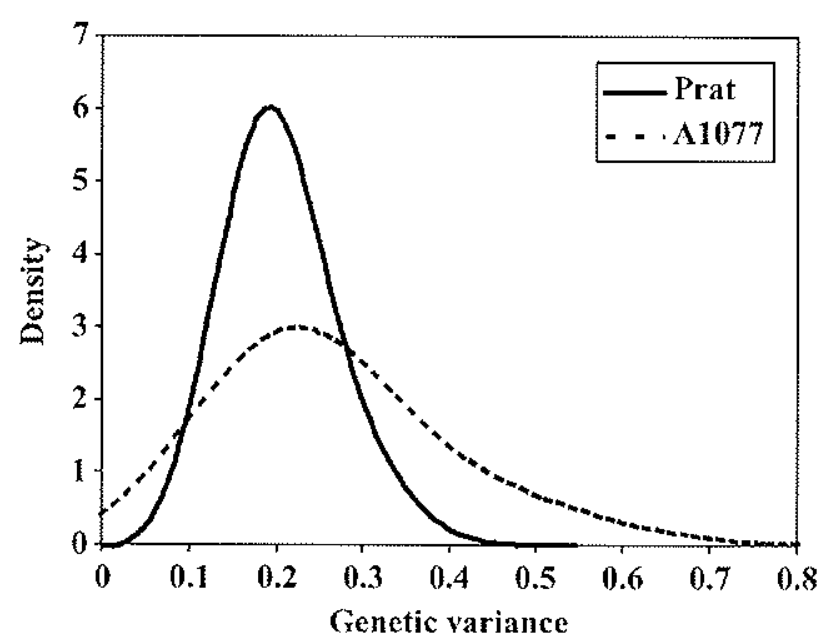

Figure 7. Gram-Charlier approximation of the marginal posterior density of the genetic variance with a model including physiological status $\times$ cycle interaction.

model. There are inflection points in the estimated survival function that are due to the fact that a doe with some pathology is more likely to be culled during unproductive periods. Low fertility does showed a lower survival probability than does pregnant at first service all throughout the productive life. The increase in culling risk associated with this effect becomes progressively lower over time. The same pattern was observed by Sánchez et al. (2004). Does nonpregnant $28 \mathrm{~d}$ after kindling had a greater risk of culling than does pregnant within $28 \mathrm{~d}$ after kindling, and delays at the beginning of productive life had negative effects throughout the life of the doe. For the A1077 line (Figure 6), the relative risk increased for nonsuckling does (corresponding to unsuccessful AI). This result can mainly be explained

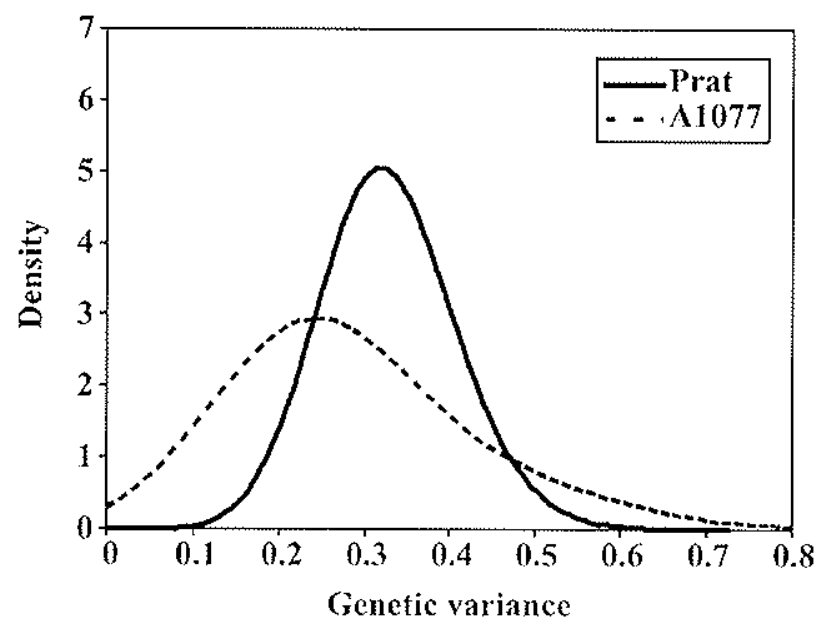

Figure 8. Gram-Charlier approximation of the marginal posterior density of the genetic variance with a model including cycle effect.

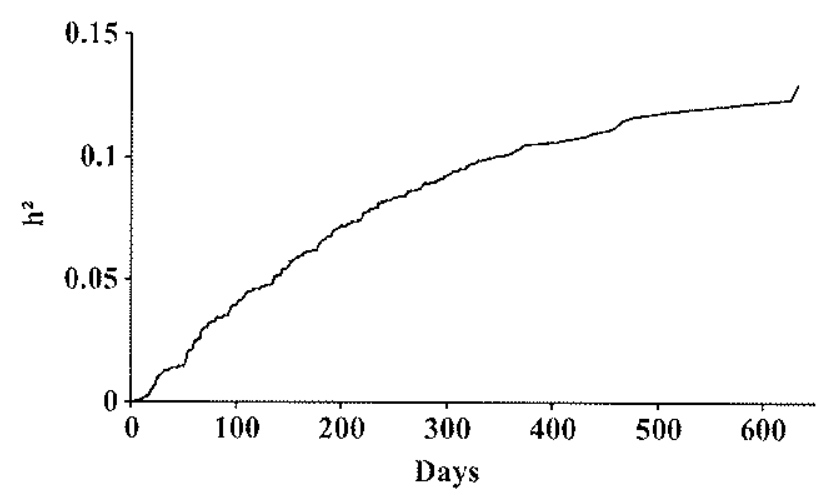

Figure 9. Effective heritability $\left(h^{2}\right)$ of length of productive life from first fertile mating in the Prat line.

by the voluntary culling of the does after 3 unsuccessful AI. 'Thus, fertility problems often appear in does in poor condition in which the risk of culling or death is greater.

\section{Relative Risk for Age at First Fertile Mating Effect}

Estimates of the regression coefficients for age at first mating and age ${ }^{2}$ effects in the Prat line were 0.037 and -0.000092 , respectively. The corresponding estimate for age at first successful AI effect in line A1077 was 0.0057 . Does beginning their reproductive life at a later age had a greater culling risk, so productive life was longer for does beginning at an earlier age. A 10-d delay increases culling risk by $36 \%$ in the Prat line, and in the A1077 line, a 42-d delay (i.e., 1 cycle) increases the culling risk by $24 \%$. Similar results were found in pigs (Yazdi et al., 2000): increased age at first farrowing increased culling risk. This result was contradictory to the hypothesis that an early first mating or AI may impair the reproductive life of does, and the older the does at first mating, the lower the risk of culling (Sánchez et al., 2004). In their study, age at first mating was the date at first mating attempt of males, without considering success or failure of the first insemination. For the A1077 line, as well as for the Prat line, a greater age may reflect a fertility problem, because age in these lines was in fact the age at first successful AI or at first positive pregnancy.

\section{Genetic Parameters}

Estimates of variance associated with the animal effect and effective heritabilities are shown in Table 3 for the Prat and A1077 lines with 2 models of analysis considered for each line. The results obtained in the Prat and A1077 lines were quite similar despite differences in breeding schemes, voluntary culling rules, definition of reproductive longevity, and modeling of the baseline hazard function. However, the genetic variance was affected by the physiological status of the female in the Prat line, which was not the case in the 
Table 3. Summary statistics of the estimated marginal posterior distributions of the variance associated with the animal effect and effective heritability for the traits length of productive life (Prat line) and number of Al from first fertile mating or Al (A1077 line)

\begin{tabular}{lcccc}
\hline \hline Fixed effect & Mode & Mean & SD & $h^{2}$ \\
\hline Prat line & & & & \\
YS + LS + PSC + AGE + AGE & 0.1879 & 0.2056 & 0.0682 & 0.158 \\
YS + IS + C + AGE + AGE & 0.3116 & 0.3289 & 0.0769 & 0.237 \\
A1077 line & & & & \\
YS + CO + LS + PSC + AGE & 0.2072 & 0.2629 & 0.1411 & 0.172 \\
YS + CO + LS + C + AGE & 0.2299 & 0.2829 & 0.1426 & 0.187 \\
\hline
\end{tabular}

${ }^{1} \mathrm{YS}=$ year-season; $\mathrm{CO}=\mathrm{cohort} ; \mathrm{LS}=$ litter size $\mathrm{C}=$ cycle; $\mathrm{PSC}=$ physiological status $\times$ cycie interaction; $A G E=$ age at first fertile mating.

A1077 line. Including age and $\mathrm{age}^{2}$ in the model had a marginal effect on variance estimates in both lines. In the Prat line, correcting for physiological status of the female removed about $40 \%$ of the genetic variance. If it had been $100 \%$, we could have concluded that the genetic differences were completely expressed through the physiological status. If it had been $0 \%$, we would have concluded that culling risk did not change with genetic differences in physiological status at the same time. Hence, genetic differences for LPL were only partly related to the way in which the risk of females changed with physiological status. In the A1077 line, only a small difference in genetic variance was observed when physiological status was included in the model. We can speculate that a smaller genetic correlation between longevity and fertility exists in this line. More research is needed to test this hypothesis.

The marginal posterior distributions of genetic variances are shown in Figure 7 for the model with the PSC interaction and in Figure 8 for the model with the cycle effect. The precision was greater in the Prat line due to a larger number of records, but considering the similarities between the lines, results obtained for the A1077 line, though less accurate, were encouraging. Using REML methodology, Youssef et al. (2000) estimated heritabilities of 0.08 and 0.13 for number of litters and length of productive life, respectively, in rabbits. In pigs, Yazdi et al. (2000) found estimates of heritability for length of productive life varying from 0.109

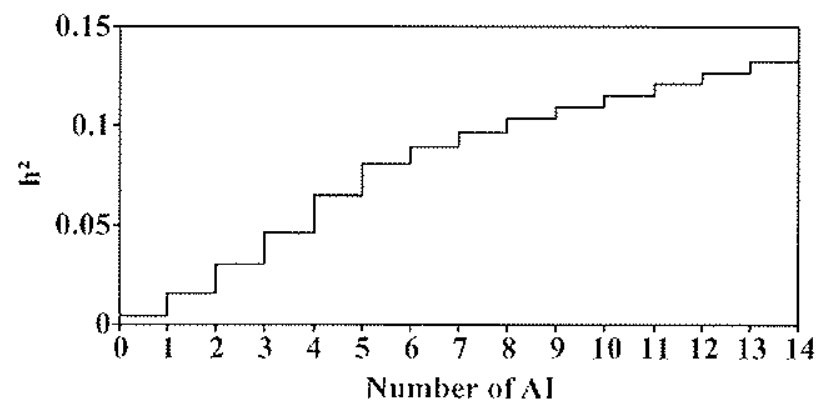

Figure 10. Effective heritability $\left(h^{2}\right)$ of the number of Al from first Al in the A1077 line. to 0.268. In rabbits, Sánchez et al. (2004) estimated the mode of the sire variance to be 0.022 . Using the formula from Yazdi et al. (2002), their estimated heritability $\left(\mathrm{h}^{2}=0.086\right)$ was lower than values obtained in the Prat and A1077 lines. These heritability estimates are maximum values, considering that all records are uncensored. In reality, increasing censoring rate decreases the heritability estimate. The increases in equivalent heritability with time or number of $\mathrm{AI}$ are shown in Figures 9 and 10 for the Prat and A1077 lines, respectively. Though the maximum heritability was greater in the Prat line, the equivalent heritability was the same in both lines due to different censoring rates. Considering a $50 \%$ censoring rate (i.e., $8 \mathrm{AI}$ in the $\mathrm{A} 1077$ line and $250 \mathrm{~d}$ in the Prat line), the heritability estimate would be around $10 \%$, which might lead to efficient selection for longevity. In a selection program, the number of $\mathrm{Al}$ or days recorded for longevity should result from a balance between reliability, partly determined by heritability and thus by censoring rate and by family structure, and generation interval. Before including such a criterion in breeding programs, the genetic relationships with other traits of interest, especially LS, must also be known. Based on previous published results, one might expect that this relationship should be null or favorable.

\section{IMPLICATIONS}

Increasing reproductive longevity, defined as the ability of the female to delay involuntary culling, is desirable in meat rabbit populations. In this study, it was shown that genetic variation exists for the traits length of productive life and number of artificial inseminations from first fertile mating or artificial insemination, both considered as measures of reproductive longevity. In the model of analysis, the combination of number of cycles and physiological status of the female seems to have an important effect on length of productive life. With an equivalent heritability of 9 to $10 \%$ (with 50\% censoring), selection for increasing longevity should be possible in some breeding schemes. To limit generation interval, early predictors of longevity should be sought. The relationship between reproductive lon- 
gevity and fertility remains unclear and needs fur. ther investigation.

\section{LITERATURE CITED}

Ducrocq, V. 1999. Extension of survival analysis to discrete measures of longevity. Fourth International Workshop on Genetic Improvement of Functional Traits in Cattle: Longevity, Jouy-enJosas, May 9-11, 1999, Interbull Bulletin No. 20, 41-47. Interbull, Uppsala, Sweden.

Ducrocq, V., and J. Sökner. 1998. The Survival Kit V3.0, a package for large analyses of survival data. Pages 447-450, Vol. $27 \mathrm{in}$ Proc. 6th World Congr. Appl. Livest. Prod., Armidale, Australia.

Farid, A., D. C. Crober, H. Van der Steen, D. L. Patterson, and M. P. Sabour. 2002. Reproductive performance of mice selected for reproductive longevity. CD-KOM communication no. 8-13 in Proc. 7th World Congr. Appl, Livest. Prod., Montpellier, France. Universidad Politécnica de Valencia, Valencia, Spain.

Garreau, G., C. Larzul, and V. Ducrocq. 2001. Analyse de longévité de la souche de lapins INRA 1077. Pages 217-220 in 9èmes Journ, Rech. Cun., Paris, France. Itavi, Paris, France.

Gómez, E. A., O. Rafel, and J. Ramon. 2002. The Prat strain (Spain). Options Mediterranéenes. Pages 199-208 in Rabbit Genetic Resources in Mediterranean Countries. Series B, Vol. 38. M. Khalil and M. Baselga, ed. Instituto Agronómico Mediterraneo de Zaragoza, Spain.

Gröhn, Y.T., V. Ducrocq, and J. A. Hertl. 1997. Modelling the effect of a diseasc on culling: An illustration of the use of time-dependent covariates for survival analysis. J. Dairy Sci. 80:1755-1766.

Klein, J. J., and M. L. Moeschberger, 1997. Survival analysis techniques for censored and truncated data. Springer Verlag, New York, NY.

Lukefahr, S. D., and H. H. Hamilton. 2000. Longevity and cumulative litter productivity in straightbred and crossbred Califomian and New Zealand white does. Pages $463-468$ in Proc. 7 th World
Rabbit Congr., Vol. A, Valencia, Spain. Universidad Politécnica de Valencia, Valencia, Spain.

Prentice, R. I., and I. A. Gloeckel. 1978. Regression analysis of grouped survival data with application to breast cancer data. Biometrics 34:57-67.

Rafel, O., M. Piles, and J. Ramon. 2001. GTE espagnole 1999: Une amée en suspens. Cuniculture 158:79-82.

Rochambeau, H., R. Duzert, and F. Tudela. 1998. Long term selection experiment in rabbit, estimation of genetic progress on litter size at weaning. Proc. 6th World Congr. Genet. Appl. Livest. Prod. 26:112-115.

Rosell, J. 2003. Health status of commercial rabbits in the Iberian peninsula. A practitioner's study. World Rabbit Sci. 11:157-169.

Sánchez, J. P., R. Peiró, M. A. Silvestre, and M. Baselga. 2004. Analysis of factors influencing longevity of rabbit does. Livest. Prod. Sci. 90:227-234.

Tudela, F., J. Hurtaud, G. Garreat, and H. de Rochambeau. 2003. Comparaison des performances zootechniques de femelles parentales issues d'une souche témoin et d'une souche sélectionnée sur la productivité numérique. Pages 53-56 in Proc. 10èmes Journ. Rech. Cun., Paris, France.

Yazdi, M. H., L. Rydhmer, E. Ringmar-Cederberg, N. Lundeheim, and K. Johansson. 2000. Genetic study of longevity in Swedish Landrace sows. Livest. Prod. Sci. 63:255-264.

Yazdi, M. H., R. 'Thompson, V. Ducrock, and P. M. Visscher. 1999. A comparison of two survival analysis methods with the number of lactations as a discrete time variate. Interbull Bull. 21:48-51.

Yazdi, M. H., P. M. Visscher, V. Ducrocq, and R. Thompson. 2002. Heritability, reliability of genetic evaluations and response to selection in proportional hazard models. J. Dairy Sci. $85: 1563-1577$.

Youssef, Y. M. K., M. H. Khalil, E. A. Afif, A. M. E. El-Raffa, and M. Zaheds. 2000 . Heritability and non genetic factors for lifetime production traits in New Zealand white rabbits raised in intensive system of production. Pages $497-503$ in Proc. 7tla World Rabbit Congr., Vol A, Valencia, Spain. 